\title{
Revisão integrativa das publicações científicas sobre Políticas Públicas no âmbito do cotidiano do agricultor familiar de Minas Gerais
}

\author{
Integrative review of scientific publications on Public Policy in farmer's everyday reach \\ of family Minas Gerais
}

\begin{abstract}
Resumo
Nas últimas décadas, diversas políticas públicas vêm sendo abordadas e discutidas, principalmente, no que se refere à agricultura familiar, que visa 0 desenvolvimento socioeconômico, acarretando transformações na vida cotidiana das famílias agrícolas. Dessa forma, este estudo teve o objetivo de analisar as produções científicas nacionais sobre as políticas públicas voltadas à agricultura familiar e sua transformação cotidiana, na região de Minas Gerais. O método utilizado foi o da revisão integrativa na literatura, analisou-se 14 artigos publicados entre 2009 e 2015, selecionados nas bases de dados: SciELO e Web of Science. Os resultados encontrados constataram que a relação entre políticas públicas e agricultura familiar é o que tem maior ênfase, porém é pouco explorado o cotidiano dos agricultores. As citações com esse foco são ainda incipientes, haja vista o número escasso de pesquisas voltadas a explorar unicamente esse assunto, sobretudo ao considerar os trabalhos analisados.
\end{abstract}

Palavras-chaves: Políticas Públicas; Agricultura Familiar; Cotidiano.

\begin{abstract}
In the last decades several public policies have been approached and discussed, mainly, with regard to family agriculture, which aims at socioeconomic development, causing changes in the daily lives of agricultural families. Thus, this study aimed to analyze the national scientific production, which focuses on the public policies focused on family agriculture and its daily transformation, focusing on the region of Minas Gerais. The method used was the integrative review in the literature, which used as reference 14 articles for analysis, selected in the databases: SciELO and Web of Science, which considered the publications between 2009 and 2015. The results found that the relationship between policies public and family agriculture is the one that has the greatest emphasis, but the daily life of the farmers is little explored. The citations with this focus are still incipient, due to the scarce number of researches focused on exploring this subject alone, especially when considering the works analyzed.
\end{abstract}

Keywords: Public Policies; Family farming; Daily.

\footnotetext{
${ }^{1}$ Mestra em Economia Doméstica pela Universidade Federal de Viçosa. Assistente administrativa na Universidade Federal de Viçosa. E-mail: rosaria.bastos@ufv.br

2 Doutora em Engenharia de Produção pela Escola Politécnica da USP. Professora do Programa de Pós-Graduação em Economia Doméstica da Universidade Federal de Viçosa. E-mail: abifano@ufv.br

3 Doutora em Economia Aplicada pela Universidade Federal de Viçosa. Professora do Programa de Pós-Graduação em Economia Doméstica da Universidade Federal de Viçosa. E-mail: mdora@ufv.br
} 


\section{INTRODUÇÃO}

Com o aumento acelerado das políticas públicas nos últimos anos, estimulado pela transição democrática, ocorreu crescimento dos estudos acadêmicos na área de políticas públicas (ARRETCHE, 1999, 2001 e 2003; SOUZA, 2003). Porém, em cenário de constantes mudanças, é desafio estabelecer políticas públicas no Brasil que realmente auxiliem e protejam a integridade do ser humano.

Política pública é definida como um conjunto de decisões e ações relativas à formulação de propostas, tomada de decisões e implementação por organizações públicas com foco nas necessidades que visam à coletividade (SOUZA, 2006; RUA, 2009). Essas ações são de responsabilidade do Estado, que tem o papel de desenvolver ações e intervenções que atendam às necessidades e aos interesses comuns da sociedade (TEIXEIRA, 2002; SECCHI, 2010). Ou seja, é o Estado que determina como os recursos serão utilizados para o benefício de seus cidadãos; que elabora, de tal modo, diretrizes norteadoras de ações para enfrentar um problema público, utilizando-se de diversos instrumentos, como leis, programas políticos e projetos.

Em razão das reivindicações de grupos rurais e movimentos sociais, o governo vem formulando e implementando diversas políticas públicas voltadas para agricultura familiar, com a finalidade de contribuir para o desenvolvimento rural, tanto para geração de emprego e renda quanto a permanência da família no campo (GRISA, 2012).

No que diz respeito à agricultura familiar, é necessário compreender as maneiras que os agricultores têm se organizado, em sua vida cotidiana, para se ajustarem às políticas públicas em que estão inseridos. Nesse sentido, é importante entender o conceito de agricultura familiar como unidades de produção rural, estruturadas no trabalho familiar, que se identificam pela relação entre terra, trabalho e família (MESQUITA; MENDES, 2012). Abramovay (1998) destaca, ainda, que a agricultura familiar é a ligação entre a gestão, a propriedade e o trabalho sob o controle da família, e que existe, também, uma complementaridade entre os papéis exercidos pela agricultura familiar e o Estado.

Portanto, o que se denomina agricultura familiar são as organizações rurais que vivem do trabalho familiar, em que se combinam expectativas de que as realizações de suas vidas podem estar vinculadas a esse. Segundo Meireles (2013, p. 2), é por meio do "trabalho que são estabelecidas relações com a natureza e criados mecanismos indispensáveis para a sobrevivência da unidade familiar". Dessa forma, o agricultor vê a possibilidade de transformação, pois, de acordo com Antunes (1995, p. 121), "o ato de produção e reprodução da 
vida humana realiza-se pelo trabalho. É a partir do trabalho, em sua cotidianidade, que o homem se torna ser social, distinguindo-se de todas as formas não humanas".

As pesquisas contemporâneas têm buscado analisar o modo de vida e o de ser dos sujeitos, assim como a vivência e o cotidiano deles. Os pesquisadores valorizam as falas, os discursos, o modo de vida dos atores sociais e as práticas cotidianas desses. Para auxiliarem nessa interface, utilizam-se métodos como a etnografia, a história oral, as conversas informais, a observação direta e participativa, dentre outros.

A visão do cotidiano que se pretende obter neste trabalho não consiste em mero estudo sobre o dia a dia ou descrição de fatos vividos pelos agricultores familiares, mas no cotidiano inserido na dinâmica das transformações cognitiva, econômica, política ou cultural, em que o habitual é cheio de significados sociais que faz e refaz o viver humano. Assim, este estudo teve como aporte teórico o autor Michel de Certau, bem como outros, para a construção do cotidiano.

Diante do exposto, esta pesquisa teve por objetivo analisar as produções científicas nacionais que apontam sobre as políticas públicas voltadas à agricultura familiar e sua transformação cotidiana, na região de Minas Gerais. Como auxílio nas referenciais atualizadas sobre o tema, recorreu-se à revisão integrativa de literatura, que vem sendo utilizada nas últimas décadas.

\section{PROCEDIMENTOS METODOLÓGICOS}

A revisão integrativa é um método específico, que permite resumir o passado da literatura, fornecendo compreensão mais abrangente de um fenômeno particular, ou seja, reúne e analisa resultados de estudos acerca de uma questão ou tema específico, de modo ordenado, possibilitando, em um só estudo, inúmeras visões, de forma abrangente, do conteúdo investigado (BOTELHO; CUNHA; MACEDO, 2011; MENDES; SILVEIRA; GALVÃO, 2008; WHITTEMORE; KNAFL, 2005).

O método da revisão integrativa vem sendo utilizado, tanto nas áreas de saúde e educação quanto em outras áreas do saber, como no campo organizacional, por estar com base na capacidade de sistematizar o conhecimento científico (BOTELHO; CUNHA; MACEDO, 2011).

Para realizar este estudo, optou-se pelo método da revisão integrativa, com base em Botelho, Cunha e Macedo (2011); Mendes, Silveira e Galvão (2008); e Whittemore e Knafl (2005), o qual compreende seis etapas percorridas de formas distintas: estabelecimento da questão de pesquisa e objetivos da revisão integrativa; criação de critérios de inclusão e exclusão de artigos (triagem e seleção da amostra); definição das informações a serem extraídas dos artigos 
selecionados; análise dos resultados; interpretação dos resultados; e apresentação da revisão e síntese do conhecimento.

Para nortear a pesquisa, formulou-se a seguinte questão: verificar o que as produções científicas nacionais apontam sobre a abordagem da temática "Políticas públicas voltadas à agricultura familiar e suas transformações cotidiana, na região de Minas Gerais".

Inicialmente, foi efetuada busca online, por meio de acesso aos portais da Scientific Electronic Library Online (SciELO) e Web of Science, a fim de selecionar os principais artigos associados às políticas públicas destinadas à agricultura familiar e às mudanças na vida cotidiana dessas famílias. Foram encontrados e selecionados 269 artigos, a partir da busca na SciELO, visando os artigos publicados nas revistas editadas no Brasil com melhores indexações, e na Web of Science, apontando os periódicos integrais assinados pela CAPES, por meio da combinação dos descritores, com aspas, "Políticas Públicas and Agricultura Familiar", "Agricultura familiar and vida cotidiana" e "Políticas Pública, Agricultura Família and Cotidiano", no intervalo de 2009 a 2015 e que tiveram relação com o tema proposto.

Dos 269 artigos iniciais, 57 permaneceram, os quais foram selecionados utilizando-se como critério, para filtragem mais específica, leitura dos títulos e resumos das produções científicas que atendiam às normas de inclusão estabelecidas, a saber:

a) Artigos de periódicos com textos publicados em português, com O objetivo de verificar aquelas produções veiculadas no país.

b) Artigos que tratassem do tema no âmbito do Estado de Minas Gerais.

c) Artigos publicados no período entre janeiro de 2009 e maio de 2015. Este período foi definido por possuir dados mais atualizados sobre o assunto em pauta.

Após esta outra triagem, foram excluídos 43 artigos dos 57 selecionados, conforme os critérios de publicações duplicadas, nas bases de dados, os quais não atendiam aos critérios de inclusão e que não contemplavam o tema investigado, FORAM selecionados 14 artigos que compuseram este estudo. Dos 14 trabalhos restantes e referentes ao tema em estudo, cinco foram da SciELO e nove da Web of Science, organizados no Quadro 1, contendo as variáveis: título, autor(es), método, objetivo e publicação/ano, relacionadas com o objeto de estudo: políticas públicas, agricultura familiar e cotidiano, que serão aportes para toda discussão deste trabalho.

Para o tratamento dos dados, fez-se leitura pormenorizada de todos os artigos selecionados, a fim de verificar a aderência e consistência com o objetivo desta pesquisa. As ideias foram agrupadas por similaridade, de maneira a compor síntese narrativa dos resultados e da discussão do conhecimento atual sobre as Políticas Públicas, Agricultura Familiar e 
Cotidiano, na região de Minas Gerais, conforme Quadro 1, apresentado a seguir. Por se tratar de uma revisão integrativa de literatura, não ocorreu envolvimento direto de seres humanos como sujeitos do estudo, não havendo, pois, necessidade de aprovação da investigação por um Comitê de Ética em Pesquisas com Seres Humanos.

Quadro 1 - Principais considerações dos artigos selecionados para o estudo

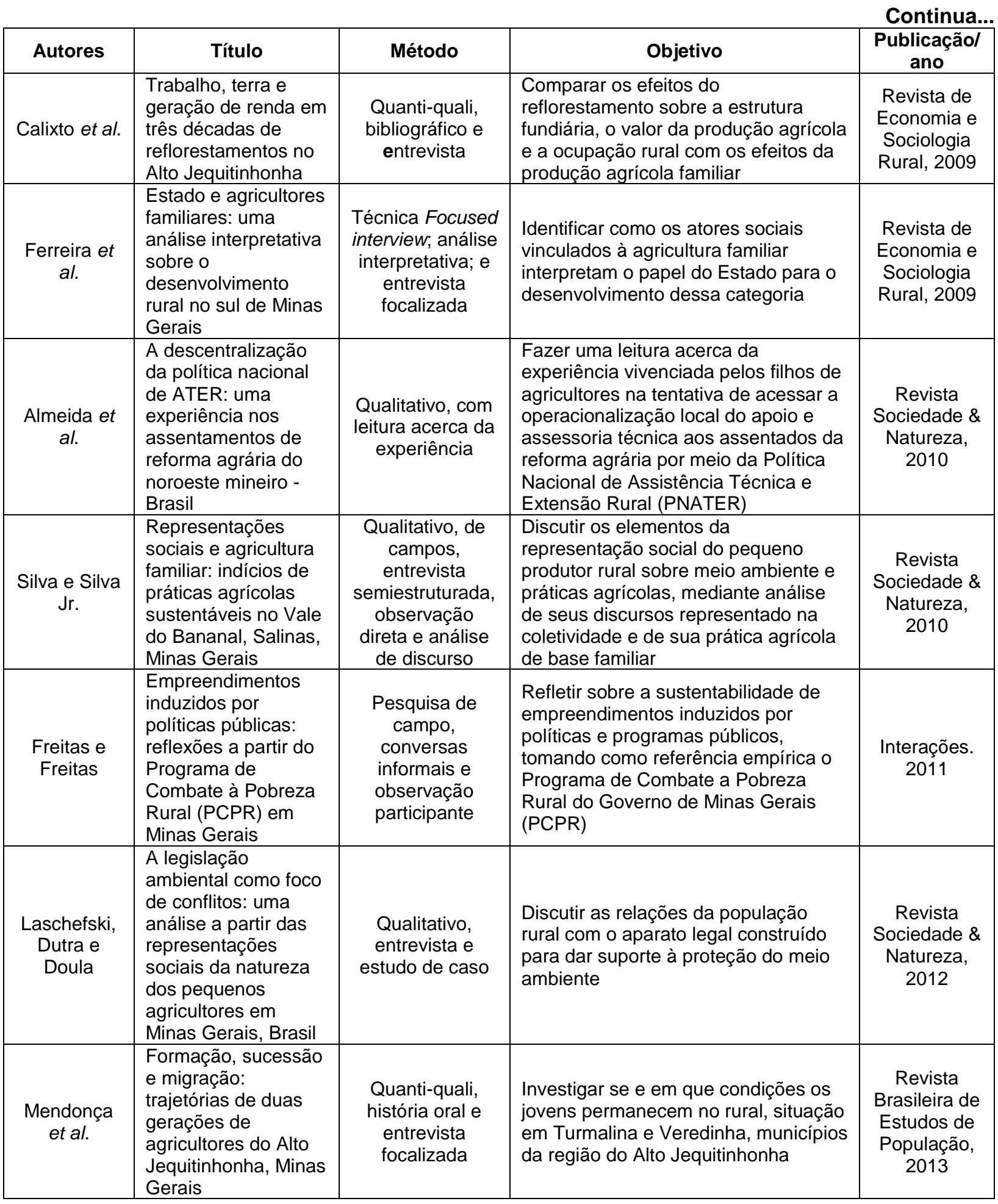


Quadro 1 - Principais considerações dos artigos selecionados para o estudo

\begin{tabular}{|c|c|c|c|c|}
\hline & & & & Conclusão \\
\hline Autores & Título & Método & Objetivo & $\begin{array}{c}\text { Publicaçã } \\
\text { o/ } \\
\text { ano }\end{array}$ \\
\hline $\begin{array}{l}\text { Freitas e } \\
\text { Freitas }\end{array}$ & $\begin{array}{l}\text { Interações entre } \\
\text { organizações } \\
\text { coletivas na } \\
\text { promoção do } \\
\text { desenvolvimento } \\
\text { local }\end{array}$ & $\begin{array}{l}\text { Qualitativo, } \\
\text { estudo de caso, } \\
\text { entrevista } \\
\text { semiestruturada, } \\
\text { observação } \\
\text { participante e } \\
\text { análise de } \\
\text { conteúdo }\end{array}$ & $\begin{array}{l}\text { Compreender como a criação de um } \\
\text { arranjo organizacional cooperativo } \\
\text { pode contribuir para o fortalecimento } \\
\text { de organizações de agricultura familiar } \\
\text { (ECOSOL); e imprimir um caráter } \\
\text { específico à dinâmica do } \\
\text { desenvolvimento local sustentável de } \\
\text { Espera Feliz (MG) }\end{array}$ & $\begin{array}{c}\text { Interações, } \\
2013\end{array}$ \\
\hline $\begin{array}{l}\text { Freitas e } \\
\text { Freitas }\end{array}$ & $\begin{array}{l}\text { Os alicerces } \\
\text { sociopolíticos do } \\
\text { cooperativismo de } \\
\text { crédito rural solidário } \\
\text { na Zona da Mata de } \\
\text { Minas Gerais }\end{array}$ & $\begin{array}{l}\text { Qualitativo, } \\
\text { estudo de caso, } \\
\text { entrevista } \\
\text { semiestruturada, } \\
\text { análise } \\
\text { documental e } \\
\text { observação } \\
\text { participante } \\
\end{array}$ & $\begin{array}{l}\text { Analisar os processos e a estrutura } \\
\text { social que sustentaram e } \\
\text { condicionaram a constituição e a } \\
\text { atuação das cooperativas de crédito } \\
\text { vinculadas ao sistema ECOSOL na } \\
\text { Zona da Mata mineira }\end{array}$ & $\begin{array}{l}\text { Revista de } \\
\text { Economia } \\
\text { e } \\
\text { Sociologia } \\
\text { Rural. } \\
2013\end{array}$ \\
\hline $\begin{array}{c}\text { Rodrigues e } \\
\text { Thé }\end{array}$ & $\begin{array}{l}\text { Veredas, oásis do } \\
\text { sertão: conflito } \\
\text { ambiental na } \\
\text { apropriação das } \\
\text { águas em Botumirim, } \\
\text { MG }\end{array}$ & $\begin{array}{l}\text { Quanti-quali, } \\
\text { etnográfico }\end{array}$ & $\begin{array}{l}\text { Analisar a influência das práticas de } \\
\text { uso e manejo tradicionais dos } \\
\text { recursos hídricos no processo de } \\
\text { construção de identidade e } \\
\text { territorialidade de duas comunidades } \\
\text { veredeiras }\end{array}$ & $\begin{array}{l}\text { Revista } \\
\text { Sociedade } \\
\quad \& \\
\text { Natureza, } \\
2014\end{array}$ \\
\hline $\begin{array}{l}\text { Silva, Dias e } \\
\text { Silva }\end{array}$ & $\begin{array}{l}\text { Relações e } \\
\text { estratégias de (des) } \\
\text { envolvimento rural: } \\
\text { políticas públicas, } \\
\text { agricultura familiar e } \\
\text { dinâmicas locais no } \\
\text { município de Espera } \\
\text { Feliz, MG }\end{array}$ & $\begin{array}{l}\text { Qualitativo, } \\
\text { pesquisa } \\
\text { documental, } \\
\text { entrevista } \\
\text { semiestruturada } \\
\text { e observação } \\
\text { participante }\end{array}$ & $\begin{array}{l}\text { Caracterizar e analisar os processos } \\
\text { estabelecidos entre as organizações } \\
\text { de agricultores familiar do município } \\
\text { de Espera Feliz, MG, e o acesso e } \\
\text { implementação de políticas públicas } \\
\text { de desenvolvimento }\end{array}$ & $\begin{array}{l}\text { Revista de } \\
\text { Economia } \\
\text { e } \\
\text { Sociologia } \\
\text { Rural, } \\
2014\end{array}$ \\
\hline $\begin{array}{c}\text { Ribeiro et } \\
\text { al. }\end{array}$ & $\begin{array}{l}\text { Programas sociais, } \\
\text { mudanças e } \\
\text { condições de vida na } \\
\text { agricultura familiar } \\
\text { do Vale do } \\
\text { Jequitinhonha } \\
\text { mineiro }\end{array}$ & $\begin{array}{l}\text { Qualitativo, } \\
\text { pesquisa de } \\
\text { campo e } \\
\text { observação de } \\
\text { campo }\end{array}$ & $\begin{array}{l}\text { Reunir indicativos censitários, } \\
\text { amostrais, indiretos e qualitativos que } \\
\text { apontam alguns resultados dos novos } \\
\text { programas públicos para população } \\
\text { rural do Jequitinhonha mineiro, } \\
\text { evidenciando como quantidade se } \\
\text { converteu em qualidade }\end{array}$ & $\begin{array}{l}\text { Revista de } \\
\text { Economia } \\
\text { e } \\
\text { Sociologia } \\
\text { Rural, } \\
2014\end{array}$ \\
\hline $\begin{array}{l}\text { Costa, } \\
\text { Amorim Jr. } \\
\text { e Silva }\end{array}$ & $\begin{array}{l}\text { As cooperativas de } \\
\text { agricultura familiar e } \\
\text { o mercado de } \\
\text { compras } \\
\text { governamentais em } \\
\text { Minas Gerais }\end{array}$ & $\begin{array}{l}\text { Quantitativo, } \\
\text { exploratório, } \\
\text { roteiro } \\
\text { estruturado e } \\
\text { semiestruturado } \\
\text { e análise de } \\
\text { conteúdo } \\
\end{array}$ & $\begin{array}{l}\text { Traçar o perfil das cooperativas de } \\
\text { agricultura familiar em Minas Gerais e } \\
\text { analisar as principais dificuldades para } \\
\text { acessar o mercado institucional }\end{array}$ & $\begin{array}{l}\text { Revista de } \\
\text { Economia } \\
\quad \text { e } \\
\text { Sociologia } \\
\text { Rural, } \\
2015\end{array}$ \\
\hline
\end{tabular}

Fonte: Elaboração própria baseada nos dados da pesquisa (2015).

\section{RESULTADOS E DISCUSSÃO}

Durante a revisão integrativa das publicações, alguns aspectos foram identificados como relevantes para o processo de análise dos conteúdos. Assim, os artigos foram organizados, destacando alguns pontos, como abordagem metodológica, publicações por revista e pesquisas por regiões de Minas Gerais, além dos seguintes eixos temáticos: Políticas Públicas; Agricultura Familiar; e Visão Cotidiana: Políticas Públicas e Agricultura Familiar. O primeiro eixo temático 
refere-se aos estudos que mencionam as Políticas Públicas com abordagens conceituais e os programas que visam o desenvolvimento rural de Minas Gerais. O segundo eixo abrange os estudos que conceituam e expõem a Agricultura Familiar e sua relação com as políticas públicas implementadas na região mineira. Já o terceiro, compreende os trabalhos que abordam as formas que os agricultores familiares têm para reorganizarem suas práticas cotidianas e se ajustarem às políticas públicas em que estão inseridos. Ressalta-se que os artigos podem abranger mais de um eixo temático e que serão tratados adiante.

No Quadro 1, a concentração de produções nos últimos anos e a revelação da atualidade dos temas, a princípio, destacam-se as abordagens metodológicas das 14 publicações analisadas entre o período de 2009 a 2015 (FIG. 1).

Figura 1 - Distribuição dos artigos por abordagem metodológica

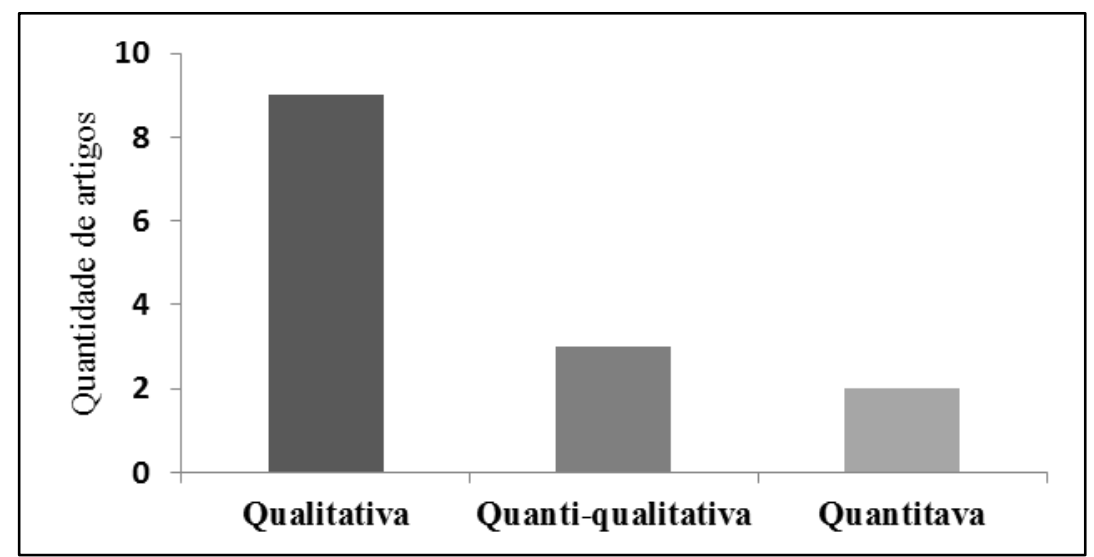

Fonte: Dados da pesquisa (2015).

Quanto ao tipo de pesquisa, observou-se que dos 14 artigos analisados, nove utilizaram abordagem qualitativa; três, abordagem quanti-qualitativa; e dois, abordagem quantitativa, utilizando procedimentos de pesquisa, como entrevistas do tipo estruturadas e semiestruturadas, questionários, estudos de caso único ou múltiplos, história oral, observação participante e direta, análise de discurso, realização de grupo focal e estudo etnográfico. Predominaram as entrevistas estruturadas e semiestruturadas. 
Figura 2 - Publicações por revista, no período de junho de 2009 a abril de 2015

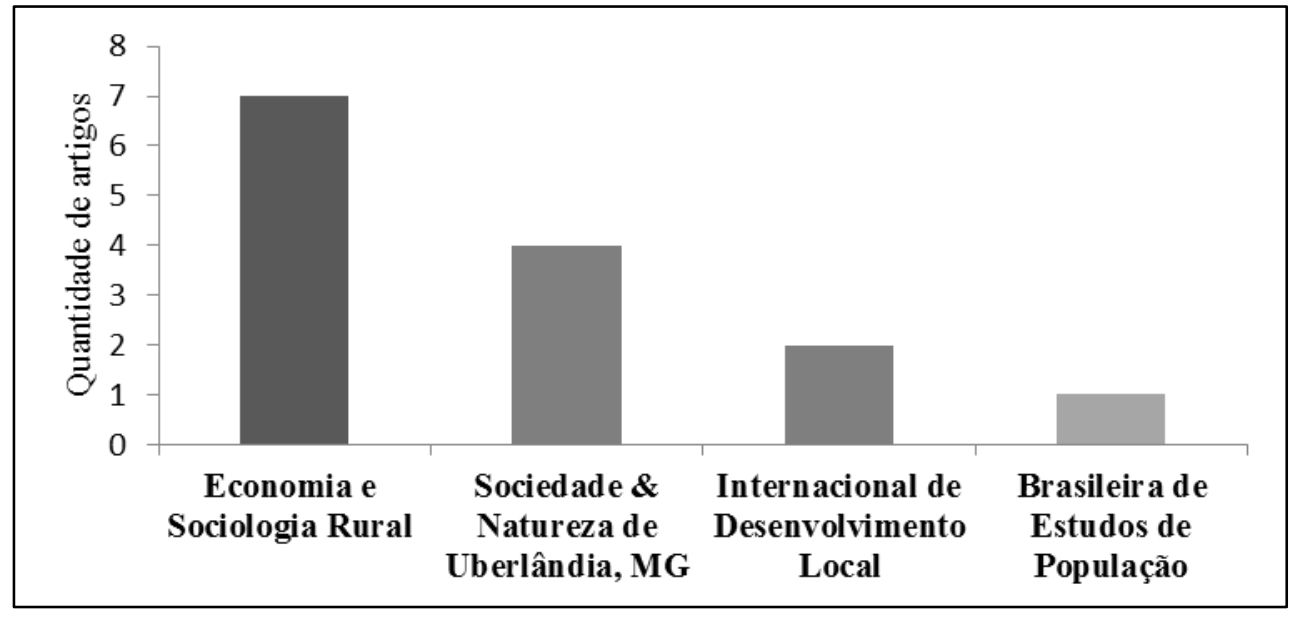

Fonte: Dados da pesquisa (2015).

Em relação ao período de publicação dos trabalhos analisados, verificou-se que, dos 14 artigos, sete foram publicados na Revista de Economia e Sociologia Rural (RESR); quatro, na Revista Sociedade \& Natureza de Uberlândia, MG; dois, na Revista Internacional de Desenvolvimento Local (Interações); e um, na Revista Brasileira de Estudos de População (REBEP). Observou-se maior relevância do tema em revistas relacionadas com a área de economia e sociologia no meio rural do que nas com o enfoque na área de estudos de população. Estes achados indicam a estreita relação existente entre a temática e as questões das Políticas Públicas no âmbito da Agricultura Familiar, a partir da realização da revisão da literatura, integrada com o objetivo deste trabalho.

Figura 3 - Levantamento bibliográfico sobre a temática "Políticas públicas voltadas à agricultura familiar e o cotidiano na região de Minas Gerais"

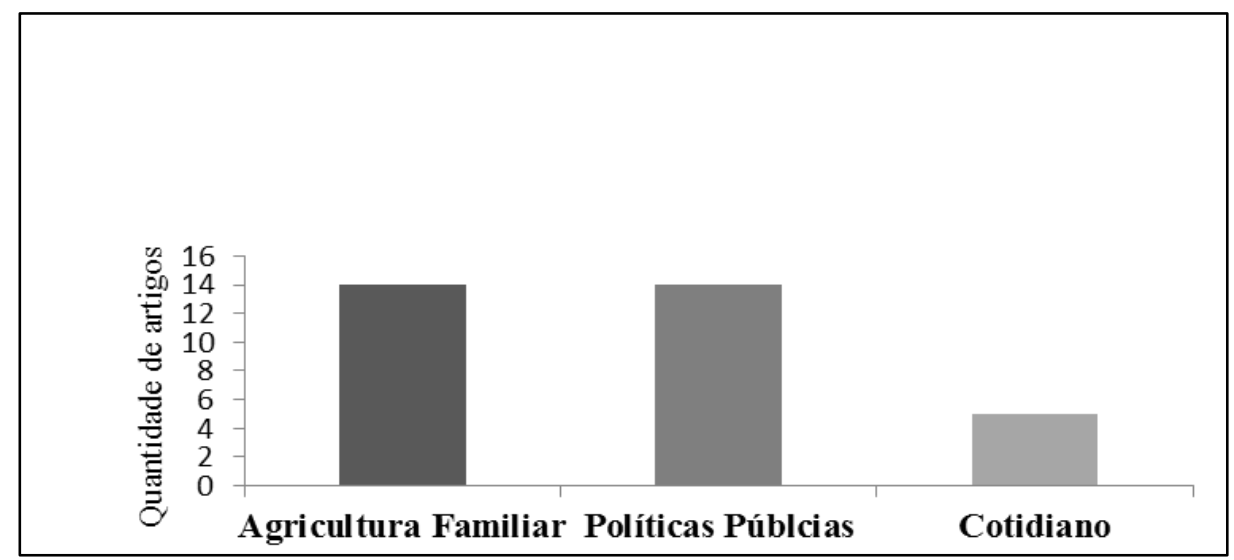

Fonte: Dados da pesquisa (2015). 


\section{POLÍTICAS PÚBLICAS}

Dos 14 artigos analisados, todos abordaram políticas públicas como relação entre o Estado e a sociedade, destacando a democracia, a descentralização do poder e as outras implicações que serão apresentados a seguir.

Segundo Simão et al. (2014), as políticas públicas decorrem da representação das relações entre Estado e a sociedade, tornando-se processo em que os governos manifestam suas intenções por meio de programas e ações, para enfrentar os problemas demandados pela população e considerado como interesse coletivo de grande importância. Para Calixto et al. (2009), a reforma do Estado tornou-se imperativa para uma mudança social na direção da modernidade e efetiva democracia. Portanto, para esses autores, a reforma do Estado deve ser entendida como superação de "visões do passado de um Estado assistencialista e paternalista", por meio da transferência da produção de bens e serviços à sociedade e iniciativa privada.

Nessa perspectiva, a Constituição Federal de 1988 tornou-se fator fundamental para democratização e descentralização brasileira, pois visa garantir os direitos civis, políticos e sociais, além de obter um novo tipo de arranjo federativo, que promova a transferência de decisões, funções e recursos do Governo Federal para os estados e municípios, o que expressa a necessidade da participação da sociedade civil (CALIXTO et al., 2009; ALMEIDA et al., 2010; SILVA; SILVA JÚNIOR, 2010; RODRIGUES; THÉ, 2014). Essa participação é corroborada por Freitas e Freitas (2011), que afirmam que tanto a participação política quanto a dos atores locais são essenciais para o revigoramento da democracia e da distribuição de responsabilidades diante dos problemas sociais. Assim, as políticas públicas, por meio dos canais de participação que se aproximam das diferenças regionais e localizadas, vão sendo aprimoradas com o tempo (RIBEIRO et al., 2014).

Nessa linha de pensamento, as publicações analisadas neste trabalho evidenciam que as políticas públicas, no âmbito da agricultura familiar, abarcaram as necessidades regionais e locais do Estado de Minas Gerais, serão apresentadas a seguir.

O Programa Nacional de Fortalecimento da Agricultura Familiar (PRONAF), abordado nas pesquisas de Ferreira et al. (2009), Simão, Silva e Silveira (2014), Silva, Dias e Silva (2014) e Costa, Amorim Júnior e Silva (2015), demonstra ser um canal que financia projetos individuais ou coletivos, visa fortalecer e desenvolver a agricultura familiar, assim como proporcionar aos pequenos agricultores familiares melhorias econômicas e sociais, além de sua fixação no campo. Hespanhol e Costa (2000) complementam que esse programa foi o marco inicial do Governo 
Federal para o fortalecimento e desenvolvimento rural, além de ter contribuído para a intensificação das análises e dos debates sobre a produção familiar no país.

Uma política pública que também se tornou um canal de aproximação do novo contexto de políticas sociais no Brasil, abordada por Simão et al. (2014), foi o Programa Fome Zero, instituída pelo Governo Federal com a finalidade de combater a fome e a pobreza, além de assegurar alimentos na mesa do povo brasileiro. O programa combina ainda políticas estruturais voltadas para as causas profundas da fome e da pobreza; políticas específicas para atender diretamente as famílias no acesso ao alimento; e políticas locais a serem implantadas por governos estaduais, prefeituras e órgãos públicos, de acordo com as necessidades de cada região. Esse programa contempla várias outras políticas públicas como o Programa de Aquisição de Alimentos (PAA) e o Programa Nacional de Alimentação Escolar (PNAE). As ações do PAA pautam pelo incentivo à produção de alimentos e, ao mesmo tempo, por sua distribuição a pessoas em risco de insegurança alimentar. Já o PNAE, restruturado em 16 de junho de 2009 pela Lei no 11.947, promove uma alimentação saudável e adequada aos alunos da rede pública de ensino sobre o atendimento da alimentação escolar pública, o que obriga estados, municípios e órgãos federais a adquirem no mínimo 30\% dos alimentos diretamente da agricultura familiar. Entretanto, ainda existem vários desafios que impedem as cooperativas de acessarem essas políticas, como assistência técnica, adequação sanitária, gestão e logísticas (COSTA et al., 2015).

A Política Nacional de Assistência Técnica e Extensão Rural (PNATER) foi descrita nos estudos de Almeida et al. (2010), como parte de agenda de desenvolvimento local, incluindo a diversidade de categorias e atividades da agricultura familiar e de ações de assessoria técnica, como experiência de descentralização de serviços de assistência técnica e extensão rural de agricultores familiares. Essa política dialoga com o município, a fim de potencializar a tentativa de novas institucionalidades por meio da criação de cooperativas de assessoria técnica, além de valorizar as iniciativas locais por meio de geração de saberes, fazeres, trabalho e renda. Esses autores concluem que as políticas públicas necessitam, ainda, de conhecer as particularidades existentes dos "lugares", para que possam promover a inclusão de "população historicamente excluída".

Com diálogo mais próximo da realidade, por meio das políticas sociais, que propõem combater a pobreza, surge o Programa de Combate à Pobreza Rural (PCPR), instituído pela parceria entre o Governo Estadual de Minas Gerais e Banco Mundial. Segundo Freitas e Freitas (2011, p. 260), esse programa financia projetos comunitários, com o objetivo principal de "ajudar os agricultores a ver e entender melhor a realidade onde vivem, a participar mais da comunidade, 
e junto com as outras pessoas, buscar alternativas e soluções para os problemas locais" (PCPR - cartilha 4, 1995). Essa é uma das políticas públicas regionalizadas que fortalece a economia da região norte de Minas e parte da região central, consideradas em situação de pobreza. Entretanto, uma das críticas enumeradas por Freitas e Freitas (2011) ao PCPR é que ao mesmo tempo em que estimula a organização social dos agricultores, promovendo o desenvolvimento rural e combate à pobreza, estimula, também, a criação de organização meramente formal, pois a inserção de recursos para associações não garante o desenvolvimento da capacidade dos agricultores familiares e tão menos o desenvolvimento rural.

As associações e as cooperativas são vistas por Freitas e Freitas (2013), Silva et al. (2014) e Costa et al. (2015) como meio para os agricultores familiares acessarem algumas políticas públicas. Esses autores definem associações e cooperativas como organizações comunitárias que se colocam, muitas vezes, na posição de mediadores sociais entre o Estado e as práticas organizativas da população e que, atualmente, dispõem de liberdade e independência. As políticas de crédito acessadas pelas associações e cooperativas analisadas são: PAA, PRONAF agroindústria, PROINF, financiamentos ao BNDES etc. Os mesmos autores ressaltaram que as cooperativas de crédito, por sua vez, condicionam os mercados locais de microfinanças rurais, 0 que interfere na mediação entre os atores e as relações de dependência financeira. Nesse sentido, o surgimento dessas organizações, no âmbito do Sindicato dos Trabalhadores Rurais (STR), é componente explicativo da relação entre as mudanças nas políticas públicas de desenvolvimento rural e a dinamicidade local (SILVA; DIAS; SILVA, 2014).

Calixto et al. (2009), Silva e Silva Junior (2010), Laschefski et al. (2012) e Rodrigues e Thé (2014), retratando as políticas ambientais que envolvem o homem e a natureza, reforçaram os conflitos socioambientais entre o Estado, por meio das políticas ambientais, e os agricultores familiar, os quais violam a legislação. Isso ocorre porque a legislação ambiental no meio rural é com base em representações da natureza de grupos hegemônicos, que não dialogam com a população, dependem de recurso ambiental para sobreviverem e não chegam a degradarem a ponto de causar destruição significativa do meio ambiente. Diante disso, concluíram que há distinção nas políticas ambientais, uma vez que os agricultores familiares disputam espaço com grandes fazendeiros e produtores agrícolas, além de a legislação não levar em conta os modos de vida e as necessidades fundamentais dos agricultores familiares.

Para Mendonça et al. (2013), o problema é a sucessão na agricultura familiar, pois os filhos e filhas de agricultores buscam oportunidades de trabalho fora do meio rural. Essa situação se deve, segundo alguns estudos abordados pelos autores, à transição demográfica, aos diferenciais de educação, à integração campo/cidade, à baixa renda e ao envelhecimento no 
campo. Esses autores recomendaram políticas públicas, voltadas para a juventude rural, capazes de integrar os jovens ao meio que conhecem.

As políticas públicas apresentadas adaptam-se às gerações de políticas públicas voltadas para a agricultura familiar abordadas por Grisa e Schneider (2015), que traçaram as três gerações de políticas públicas que visam desenvolver a agricultura familiar. A primeira geração foca no viés agrícola e agrário; a segunda geração está direcionada para as políticas públicas sociais e assistenciais; e a terceira geração tem como foco a construção de mercado institucional para segurança alimentar e sustentabilidade; além de serem políticas essas que visam aproximar e adaptar às distintas realidades sociais e regionais do país.

Entretanto, nos últimos quatro anos, o Brasil encontra-se em crise econômica, política e social, o que é preocupante para as ações instituídas pelas políticas públicas terem continuidade, principalmente as sociais. Prova disso é que há forte indício de retratação ou desmantelamentos das políticas públicas voltadas para a agricultura familiar instituídas até o momento, que pode vir a configurar retrocesso no desenvolvimento agrícola de Minas Gerais, principalmente, para o pequeno agricultor, e até mesmo para o país (APPY et al., 2015, COSTA, 2017).

\section{AGRICULTURA FAMILIAR}

De forma geral, as publicações estudadas abordaram a agricultura familiar em relação à conceituação e sua ligação com as políticas públicas implementadas no Estado de Minas Gerais. As principais ideias tratadas nos artigos estão apresentadas a seguir.

O conceito de agricultura familiar descrito por Freitas e Freitas (2013) designa a diversidade de atores, que têm em comum a ligação com o campo, com alguma atividade agrícola, com a utilização dos recursos naturais de que dispõem e com os empregos de mão de obra familiar. Para Silva, Dias e Silva (2014), a agricultura familiar corresponde ao conjunto de relações complexas em que a propriedade e o trabalho estão intimamente ligados à família.

No entanto, foi unânime para Calixto et al. (2009), Ferreira et al. (2009), Freitas e Freitas (2011), Silva, Dias e Silva (2014), Simão et al. (2014) e Costa et al. (2015) que o termo agricultura familiar surge como conceito e tem sua legitimação com a criação do PRONAF, que passa a fazer parte da agenda de políticas públicas de desenvolvimento rural, sendo unificador de diversas categorias sociais.

Para Picolotto (2015), o reconhecimento da agricultura familiar não deve ser entendido como conceito formal da categoria, definido em leis e políticas públicas, mas como processo complexo de construção de grupos ou categorias sociais rurais, que foi inferiorizado 
historicamente, e luta por se fazer reconhecer perante a sociedade e o Estado. Para esse autor, a maioria dos conceitos adotados de agricultura familiar baseia-se na direção dos trabalhos, na renda gerada pela atividade agrícola, no tamanho da propriedade e na mão de obra utilizada.

O fato é que a agricultura familiar no Brasil vem sendo discutida em seus aspectos, social, econômico e político, principalmente no meio acadêmico e no social, o termo "agricultura familiar" apresenta-se na dicotomia entre o conceito de campesinato. Segundo Fernandes (2013), estas discussões se deve a alguma referência do paradigma do capitalismo agrário, sem levar em consideração o significado dos respectivos conceitos.

Apesar da discussão dos paradigmas acadêmicos que fundamentam o termo "agricultura familiar", para as políticas governamentais voltadas para meio rural, este foi o adotado, principalmente a partir de 1990, quando o Governo brasileiro utiliza o termo "agricultura familiar" no discurso da formulação do Programa Nacional de Fortalecimento da Agricultura Familiar PRONAF (HESPANHOL; COSTA, 2000).

Posteriormente, o Governo Federal, por meio da Lei n 11.326, de 24 de julho de 2006, estabeleceu as diretrizes da Política Nacional de Agricultura Familiar e Empreendimentos Familiares Rurais. Essa política passa a definir a agricultura familiar como: (a) a praticada pelo agricultor; (b) a mão de obra utilizada nas atividades econômicas é predominantemente familiar; (c) a renda familiar deve ter percentual mínimo originário de atividades econômicas vinculadas ao próprio estabelecimento; (d) a gerência da unidade produtiva deve ser exercida pela família e (e) a área do estabelecimento não pode ser maior que quatro módulos fiscais. Esta é a caracterização que norteia a seleção de produtores que poderão ser beneficiários das políticas e programas voltados para agricultura familiar.

É notório que a agricultura familiar, no decorrer dos anos, vem demonstrando responsabilidade histórica na transferência dos espaços naturais, proporcionada pela crescente necessidade de produção de alimentos, o que a torna fundamental, tanto para a economia brasileira quanto para a melhoria na qualidade vida da população (SILVA; SILVA JÚNIOR, 2010).

Outro aspecto importante, entre os estudos analisados que abordam a temática agricultura familiar, foi a relação da agricultura familiar com as políticas públicas implementadas nas seis regiões do Estado de Minas Gerais: Nordeste, Zona da Mata, Norte, Noroeste, Campo das Vertentes e Sul de Minas Gerais (FIG. 4). 
Figura 4 - Pesquisas por regiões do Estado de Minas Gerais

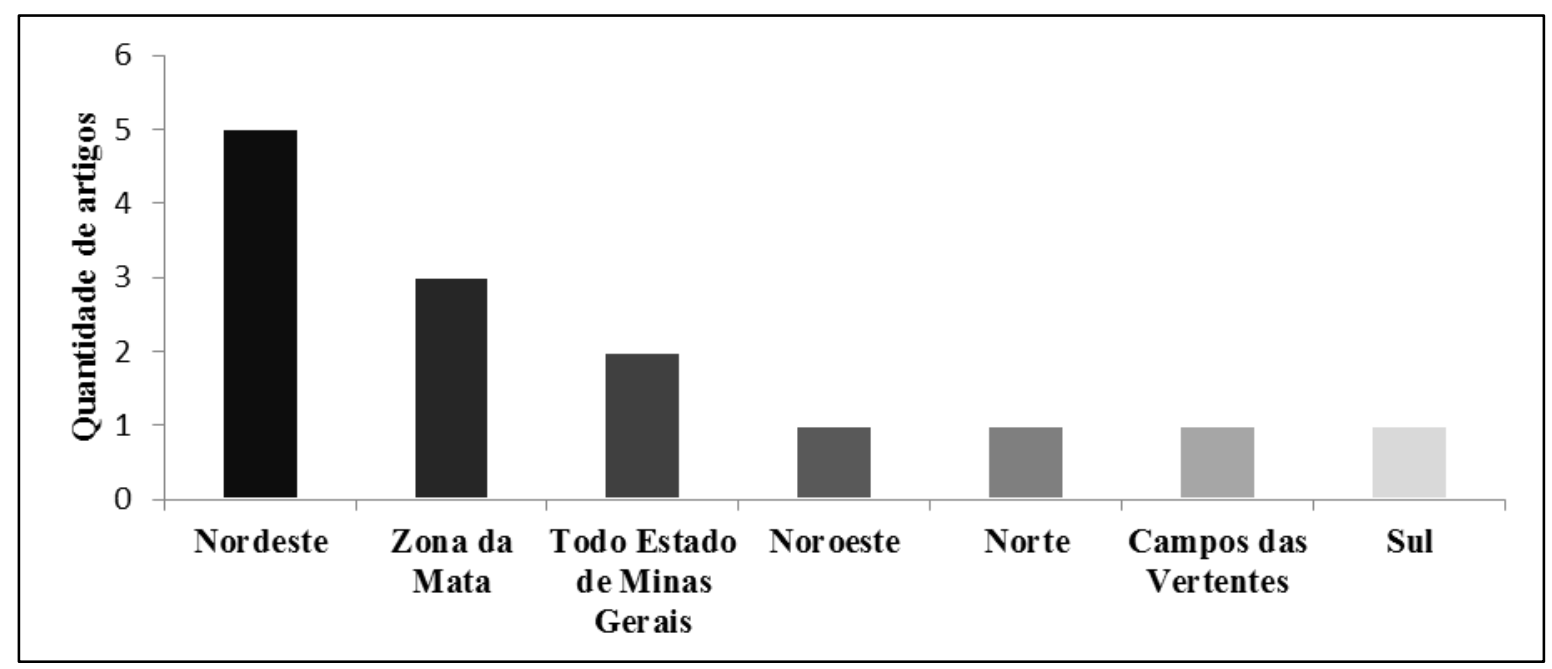

Fonte: Dados da pesquisa (2015).

Nota-se, na FIG. 4, que cinco artigos foram da região Nordeste; três, da Zona da Mata mineira; dois, de todo o Estado de Minas Gerais; um foi do Noroeste; um, do Norte; um, do Campo das Vertentes; e um, do Sul de Minas Gerais, o que apresenta as diversidades entre as regiões que serão discutidas a seguir.

A região nordeste de Minas Gerais, segundo Calixto et al. (2009), Freitas e Freitas (2011), Mendonça et al. (2013), Rodrigues e Thé (2014) e Ribeiro et al. (2014), apresenta-se economicamente atrelada à história, ao garimpo e à agricultura, em razão do ciclo de minerações. A região é composta por caatinga, cerrados, chapadões e grandes vales abertos, predominando o semiárido, com áreas planas e de baixa fertilidade; em contrapartida, é farta em recursos naturais, além de hidrelétricas e pequenos córregos que orientam a construção da territorialidade local, formando múltiplas veredas. Esses aspectos estabelecem vários sistemas agrícolas e regimes agrários, prevalecendo a agricultura familiar tradicional, que abastece tanto a população urbana quanto a rural, por meio da comercialização da produção dos agricultores familiares vendida em feiras livres. Os agricultores familiares dessa região contam ainda com o PRONAF, PNATER e PCPR, que estimulam a constituição e, ou, formalização de organizações locais, além do desenvolvimento e combate à pobreza da região. Os programas de transferências de renda chamam a atenção, como o Bolsa Família e o benefício da aposentadoria, que asseguram aos agricultores familiares e à família deles alimentos no momento de crise, garantindo, assim, as condições mínimas de existência, além de minimizar a migração sazonal da população rural dessa região, a qual busca complementação da renda familiar em outras regiões. Nesse sentido, algumas políticas públicas trouxeram mudanças significativas para 
região do nordeste de Minas Gerais, como a constituição de associações e organizações rurais, estimulando a inclusão social e produtiva.

Entretanto, os agricultores vêm enfrentado desafios com a implementação de algumas ações públicas, como projetos de formação de eucaliptais, cafeicultura, mineração, construção de barragens e reflorestamento em grandes áreas, o que tem ocasionado redução e superexploração das áreas de terras dos agricultores familiares, que perdem seus espaços nas chapadas. Essas ações não têm se revelado eficazes, gerando conflitos entre a população rural e as instituições governamentais, principalmente, com as políticas ambientais, que são formuladas sem considerar os costumes locais dessa região. Percebeu-se que ainda há muito que se fazer para que essa região deixe de ser considerada estagnada economicamente, se comparada com outras regiões agrícolas do país, um desafio para os programas públicos.

A Zona da Mata mineira é região estritamente agrária, predominantemente de agricultores familiares que caminham para a criação de associações e cooperativas, mas se encontra em processo de "estagnação econômica", conforme abordado nas pesquisas de Freitas e Freitas (2011 e 2013), Silva et al. (2014) e Simão et al. (2014). Essa afirmação é corroborada nos trabalhos de Oliveira Júnior (2011) e Brasil (2015, p. 11), os quais destacaram que os municípios localizados nessa região vêm enfrentando situações de baixa densidade econômica, ocasionando aumento do êxodo rural, despovoamento, empobrecimento e aumento das desigualdades sociais, o que os "colocam em termo de desenvolvimento social, uma região altamente pobre, se comparando com as regiões mais pobres do Estado de Minas Gerais". Freitas e Freitas (2011 e 2013), Silva et al. (2014) e Simão et al. (2014) enfatizaram que as políticas públicas, de modo geral, vêm incentivado as organizações formais da agricultura familiar e o desenvolvimento sustentável; no entanto, para potencializar essas estratégias, é preciso repensar as políticas públicas de forma a considerar as particularidades dos agricultores familiares, do local e da região, como é o caso da região da Zona da Mata. No geral, as pesquisas não abordaram características mais detalhadas da região da Zona da Mata, como clima, relevo, solo e cultivo.

Na região noroeste, relatado por Almeida et al. (2010), as políticas públicas voltadas para meio rural estão relacionadas com o PNATER, por ser região marcada por parcela considerável dos assentamentos do Estado, com acesso restrito a serviços de assistência técnica oficial. Esse programa capacita os filhos dos agricultores dos assentamentos, no que se refere à assistência técnica e, ao mesmo tempo, melhora as atividades na agricultura, transformando o grupo familiar em Cooperativa de Assistência Técnica para o Desenvolvimento Sustentável (COOPATEC). 
Entretanto, a pesquisa desses autores não abordou outras caraterísticas da região norte de Minas Gerais.

Para Silva et al. (2014), a região norte é caracterizada como região semiárida, com grande diversidade física, social, econômica e um médio Índice de Desenvolvimento Humano (IDH). A agricultura familiar dessa região é considerada precária, por pertencer ao bioma Caatinga e Cerrado, ou seja, por ter solo inadequado para as práticas agrícolas, de subsistência e tradicional, com base técnica rudimentar. Segundo os mesmos autores, há expansão da monocultura de eucalipto, por meio de investimento empresarial, tornando-se, assim, agravante para os problemas ambientais que afligem essa região. Essas constatações vêm ao encontro da pesquisa de Hespanhol e Pereira (2015), que afirmaram que esses cenários têm reforçando a concentração fundiária e a intensificação o êxodo rural, o que tem ocasionado efetiva participação do Estado na região, por meio de políticas públicas, de forma pontual e setorial, e de parcerias como a Empresa de Assistência Técnica e Extensão Rural do Estado de Minas Gerais (EMATER-MG) e Fundação Rural Mineira (RURALMINAS) (SILVA et al., 2014). Entretanto, segundo Hespanhol e Pereira (2015, p. 68), essas ações políticas, ainda "não permite investimentos estruturais para reverter às desigualdades de infraestrutura, de mercado de trabalho, de acesso à população aos serviços básicos".

No Campo das Vertentes, os pesquisadores Laschefski et al. (2012) destacaram que a base principal da economia dessa região é a agropecuária, mais importante do que a agricultura. Isso é explicado pelo relevo bastante acidentado, característico dos "mares de morros de Minas Gerais" típico da Mata Atlântica. Em 2009, essa região foi reconhecida pelo Instituto Mineiro de Agropecuário (IMA) como a produtora de Queijo de Minas, feito a partir de leite cru, não pasteurizado, intensificando ainda mais a agropecuária da região (IMA, 2009). Segundo Laschefski et al. (2012), essa região é propícia a conflitos ambientais, uma vez que os agricultores familiares, os quais sobrevivem do meio natural, violam as políticas públicas ambientais desenvolvidas nessa região, ou seja, utilizam-se dos recursos naturais com base nas vivências das populações rurais; muitas vezes, vão de encontro as interversões do Governo, por meio da legislação ambiental, resultando assim em conflitos territoriais. Os autores ressaltaram que as políticas ambientais no âmbito rural não devem equiparar o pequeno agricultor familiar aos grandes empreendimentos agrícolas, conforme vem ocorrendo em diversa legislação.

Já Ferreira et al. (2009) analisaram, nas perspectivas das categorias de atores sociais ligados à agricultura familiar, como lideranças de produtores familiares, profissionais de ciências agrárias, autoridades municipais, pesquisadores e professores universitários, a atuação do Estado no desenvolvimento da região sul de Minas Gerais, apresentando algumas limitações e 
potencialidades da agricultura familiar nessa região. A região é composta de agropecuária familiar tradicional e rica em recursos naturais, destacando o predomínio da pecuária leiteira e a cafeicultura como produção agrícola. Foram apontadas diversas dificuldades encontradas para o desenvolvimento da agricultura, como, o agricultor familiar não possui o espírito empreendedor e tem medo de se arriscar; a participação social dos agricultores familiares ainda é elementar e desarticulada; a disponibilização de recursos financeiros é insuficiente para atender às demandas dos produtores familiares; a falta de políticas agrícolas; e a pouca articulação dos agricultores familiares para reivindicarem seus direitos perante o Governo. Fatores considerados essenciais para a agricultura familiar na região, na percepção dos atores sociais, a EMATERMG, a EPAMIG, as universidades, as escolas agrotécnicas da região e o PRONAF. Porém, esses fatores não são empreendidos adequadamente, o que tem dificultado maior atuação dos agricultores familiares dessa região, reforçando a dependência da agricultura familiar em relação ao Estado, vista pelos atores sociais como Estado assistencialista e paternalista. Esses pesquisadores destacaram a necessidade de se criar mecanismo que incentive a participação social e conscientização dos produtores familiares em se mobilizarem de maneira coletiva, visando superar as dificuldades econômica, sociais e políticas dessa região.

Simão et al. (2014), considerando as políticas públicas voltadas para o agricultor familiar e a produção de alimentos, analisaram a eficiência do PAA nos municípios do Estado de Minas Gerais, os quais identificaram, em razão das peculiaridades, necessidades e limitações das regiões, comprometimento dos novos arranjos institucionais no âmbito local e regional, ou seja, a cobertura dos programas governamentais voltados para a agricultura familiar necessita de ações regionalizadas. Essa afirmação comprova o que foi descrito nos estudos de Costa et al. (2015), que analisaram as políticas de compras governamentais do PAA e PNAE para as cooperativas de agricultura familiar de todo Estado de Minas Gerais, diagnosticando vários desafios que impedem as cooperativas de acessarem essas políticas, como assistência técnica, adequação sanitária, gestão e logísticas. Percebeu-se que a existência de políticas públicas não é garantia de desenvolvimento e comercialização dos produtos da agricultura familiar, pois é necessário que se tenha acompanhamento sistemático e contínuo dessas ações, considerando tanto os aspectos por parte do Governo quanto os aspectos local e regional, que alcancem o público-alvo (SIMÃO et al., 2014; COSTA et al., 2015)

As regiões abordadas apresentam, cada uma com sua característica peculiar, processo de diferenciação entre as regiões do Estado de Minas Gerais. Esse processo vem ao encontro do trabalho de Pereira e Hespanhol (2015) que trataram sobre a região e regionalizações no Estado de Minas Gerais e suas vinculações com as políticas Públicas. Os autores trabalharam 
as características produtivas e sociais mineiras, com base na análise dos processos que redundaram no desenvolvimento regional desigual. Destacaram que a expansão das forças produtivas, ao longo da formação socioespacial brasileira, ocasionou estruturas políticas e econômicas desiguais, que foram reforçadas com a ascensão da economia urbano-industrial e a intervenção do Estado em prol do capitalismo monopolista no decorrer do século XX. Concluíram que as políticas públicas oficiais tenderam a fortalecer as desigualdades regionais em Minas Gerais ao concederem facilidades para a realização de investimentos privados em algumas regiões e marginalizarem as demais.

Assim, diante das análises apresentadas, as diferenças regionais estabelecidas no Estado de Minas Gerais e as políticas públicas nelas implementadas possuem diversos objetivos que derivam das decisões do poder governamental. Assim, quando se refere à intervenção do Governo no âmbito da agricultura familiar, é necessário repensar as ações políticas de outro formato, ou seja, de forma mais próxima da realidade e das necessidades local e regional, onde se encontram os agricultores familiares.

\section{VISÃO COTIDIANA: POLÍTICA PÚBLICA E AGRICULTURA FAMILIAR}

Com relação à análise do modo de vida dos agricultores familiares sobre a temática "Visão cotidiana: políticas públicas e agricultura familiar", as pesquisas trouxeram a discussão dos autores referente às diferentes formas que os agricultores têm para reorganizarem suas práticas cotidianas e se ajustarem às políticas públicas em que estão inseridos. Tais formas de cotidiano vão produzindo cultura de saberes no modo agrícola, de saberes produzidos pelos agricultores e seus familiares e no diálogo da vida cotidiana.

Nesse sentido, toda atividade humana pode ser cultura; no entanto, segundo Certeau (1994, p. 142), "para que haja cultura, não basta ser autor das práticas sociais; é preciso que essas práticas sociais tenham significado para aquele que as realizam". Esse discurso é confirmado por Calixto et al. (2009), que abordaram fatores favoráveis e limitantes ao desenvolvimento da agropecuária, da agricultura familiar, na região sul de Minas Gerais (RSMG), fato que permitiu aos atores sociais identificarem qualidades no desenvolvimento rural, atribuindo significados para a agricultura familiar. Esse tema também é realçado na pesquisa de Almeida et al. (2010), que fizeram leitura acerca da experiência vivida e sentida por grupos de filhos de agricultores na tentativa de acessar a operacionalização local do apoio e da assessoria técnica aos assentados da reforma agrária, por meio da PNATER no noroeste de Minas, no município de Unaí, MG. 
As ações que os agricultores desenvolvem, nos contextos cotidianos, podem ser percebidas no produto do cotidiano que se produz, o que Certeau (1994) denominou de "artes de fazer", "astúcias sutis" e "táticas de resistência", que vão transformando as maneiras de trabalhar, estabelecendo aproximação do seu ambiente e atitude ao modo de cada um. Essa invenção do cotidiano é percebida na pesquisa de Rodrigues e Thé (2014), em que os autores fazem reflexão do caso da comunidade de Gigante e Pé dá Serra, comunidade onde o ser e o saber-fazer estão vinculados ao contato direto com as nascentes de serra, veredas e curso d'Águas. A população dessa comunidade desenvolve, localmente, autonomia para a produção agrícola voltada para consumo próprio, a partir das condições naturais locais que proporcionam a criação de estratégias e táticas de produção específicas, o que pode ser comprovado na fala de um agricultor:

\begin{abstract}
Feijão das águas é plantado junto com a roça de milho, de outubro até novembro, plantado nas terras mais altas. Tem a planta de feijão das secas que já é plantado mais nas margens do rio de fevereiro até abril. E vem o temporão que é plantado na faixa de junho até princípio de agosto (...). Aqui pra nós o forte tá sendo o feijão das secas. Agora com o recurso da irrigação o temporão também tem vez que dá certo (RODRIGUES; THÉ, 2014, p. 32)
\end{abstract}

A pesquisa apresentada por Silva e Silva Júnior (2010) enfatizou como os pequenos agricultores rurais, do município de Salinas, norte de Minas Gerais, estão percebendo as questões da degradação ambiental, uma vez que as práticas agrícolas tradicionais culminam em resultados desastrosos para o meio ambiente. Esses autores analisaram a compreensão rural sem nenhum preconceito, ou seja, questionar sem contestar ou se opor ao discurso do outro, mas com o respeito à existência de saberes diversos.

Segundo Bifano e Silva (2014, p. 31), “o cotidiano é dinâmico, pois a todo o momento, o indivíduo reorganiza suas atividades de acordo com a situação, o contexto, os recursos disponíveis e seu campo de ação". Partilhando com essa visão, os autores Laschefski et al. (2012) verificaram em suas pesquisas, por meio das falas dos agricultores, essa dinamicidade da vida cotidiana, destacando ainda que há ausência de diálogo entre o poder público e a população, desconsiderando o fato de que os agricultores compartilham um modo de vida que se constrói muitas vezes à base de muito sofrimento e dificuldades enfrentadas nas atividades rurais diariamente. Laschefski et al. (2012) verificaram nas falas dos agricultores essa dinamicidade da vida cotidiana: 
fica caro (...). - (...) aos pouquinhos, o "C" vai limpando tudo lá em cima (...)" (Este agricultor se refere ao corte de madeira para venda realizada por outro agricultor (LASCHESKI et al., 2012, p. 413).

Em algumas entrevistas aplicadas na pesquisa de Laschefski et al. (2012), verificou-se que alguns agricultores usam técnicas de proteção ao meio ambiente, não por influência da legislação ambiental, mas por estarem ligadas às tradições desses. Um deles mencionou usar as cabeças de boi mortos na propriedade para construir ninhos para pássaros, de forma a evitar que eles fossem roubados enquanto filhotes. Outros agricultores afirmaram realizar plantio de árvores para proteger as nascentes. Os autores destacaram ainda que essas ações não demonstram exatamente razões relacionadas com a proteção do meio ambiente, mas sim questões práticas que correspondem às necessidades da vida diária. Assim, é necessário compreender que os praticantes do cotidiano fazem suas sínteses intelectuais não pela forma de discurso, mas pela "própria decisão, ato e maneira de aproveitar a ocasião" (CERTAU, 1994, p. 47).

Para se ter visão das transformações ou não da vida cotidiana das famílias agrícolas, é necessário pensar no diálogo dos "praticantes" (CERTEAU, 1994), que "fazem" os vários contextos da agricultura familiar. Ao contrário dos que dizem, "as políticas públicas voltadas para agricultura familiar são implementadas visando desenvolverem as famílias agrícolas e o meio rural”. É preciso saber se os agricultores familiares sabem ou percebem essa transformação.

Portanto, as pesquisas apresentadas evidenciaram que há pouco diálogo entre políticas públicas aplicadas na agricultura familiar e sua aplicabilidade real e prática no seu cotidiano, 0 que necessita de maior atenção por parte dos pesquisadores. As pesquisas focam mais na operacionalização ou efetivação das políticas públicas voltadas para agricultura familiar, do que nas transformações ocorridas na vida cotidiana das famílias agrícolas acarretadas pelas ações das políticas.

\section{CONSIDERAÇÕES FINAIS}

Os resultados, obtidos a partir das 14 publicações científicas selecionadas, constataram que a relação entre políticas públicas e agricultura familiar está recebendo maior ênfase, porém é pouco explorado o cotidiano que está inserido os agricultores. Contudo, embora diversas pesquisas tenham se referido ao cotidiano dos agricultores familiares inseridos nas políticas públicas, não foram encontradas, de modo expressivo, produções científicas que se proponham a discutir específica e praticamente essa relação. As citações com esse foco são ainda 
incipientes, haja vista o número escasso de pesquisas voltadas a explorar, unicamente, esse assunto, sobretudo, se considerado o total de trabalhos analisados.

Essa constatação parece se relacionar com o fato de que o cotidiano, enquanto fenômeno de estudo, ganhou evidência muito recentemente. Assim sendo, é possível afirmar que o diálogo entre políticas públicas aplicadas na agricultura familiar e sua aplicabilidade real e prática no seu cotidiano necessita de maior atenção por parte dos pesquisadores, tendo em vista que a análise dos dois fenômenos tem ocorrido de maneira isolada e, ou, associada a outros fatores. Desse modo, os estudos do cotidiano têm se evidenciado campo multidisciplinar, com pluralidade de influencias, na tentativa de reconstruir experiências não ponderadas.

Constata-se que o Estado de Minas Gerais vem, ao longo das décadas, buscando intervir, por meio das políticas públicas, principalmente na agricultura familiar, nas diferentes regiões do estado. As políticas públicas nelas implementadas possuem diversos objetivos, que derivam das decisões do poder governamental, que visam aproximar e adaptar às distintas realidades sociais locais e regionais, onde se encontram os agricultores familiares.

Entretanto, nos últimos quatro anos, o Brasil encontra-se em situação delicada, por causa da crise econômica, política e social, o que é algo preocupante para as ações instituídas por meio das políticas públicas terem continuidade, principalmente as políticas sociais. Pois, há forte indício de retratação ou desmantelamento das políticas públicas voltadas para a agricultura familiar instituídas até o momento, o que pode vir a configurar retrocesso no desenvolvimento agrícola de Minas Gerais e do país, conforme discutido por Appy et al. (2015) e Costa (2017).

Considerando que este estudo limitou-se a apresentar dimensões temáticas gerais dos trabalhos, sugere-se, como continuidade, a realização de análise mais aprofundada e crítica dos estudos. Fica a sugestão aos profissionais e docentes que estão envolvidos com esse processo de incentivarem a pesquisa, sobretudo, de cunho avaliativo, nessa área.

\section{REFERÊNCIAS}

ABRAMOVAY, Ricardo. Juventude e agricultura familiar: desafios dos novos padrões sucessórios. Brasília, DF: UNESCO, 1998. Google

ANTUNES, Ricardo. Adeus ao trabalho? Ensaios sobre a s metamorfoses e a centralidade do mundo trabalho. São Paulo: Cortez, 1995. Google

ARRETCHE, Marta Teresa da Silva. Políticas sociais no Brasil: descentralização em um Estado federativo. Revista Brasileira de Ciências Sociais, v. 14, n. 40, p. 111-141, 1999. [Visualizar] Google 
. Tendências no estudo sobre avaliação. In: RICO, Elizabeth Melo (org.). Avaliação de políticas sociais: uma questão em debate. São Paulo: Cortez, 2001. p. 29-39.

Dossiê agenda de pesquisa em políticas públicas. Revista Brasileira de Ciências Sociais, São Paulo, v. 18, n. 51, p. 7-9, fev. 2003.

ALMEIDA, Suênia Cibeli Ramos de; OLIVEIRA, Marcelo Nascimento de; XAVIER, José Humberto Valadares. V. A descentralização da Política Nacional de ATER: uma experiência nos assentamentos de reforma agrária no Noroeste Mineiro - Brasil. Sociedade \& Natureza, Uberlândia, MG, v. 22, n. 3, p. 551-560, dez. 2010. [Visualizar] Google

APPY, Bernard, LISBOA, Marcos de Barros, MENDES, Marcos, LAZZARINI, Sérgio. Os desafios para sair da crise. Jornal O Estado de S. Paulo. 2015. Acesso em: 05 out 2017. [Visualizar]

BIFANO, Amélia Carla Sobrinho; SILVA, Flávia Leão Almeida. Incursões sobre o estudo do cotidiano. Viçosa: Ed. UFV, 2014. 138 p. (Cadernos UNIEDHS).

BOTELHO, Louise Lira Roedel; CUNHA, Cristiano Castro de Almeida; MACEDO, Marcelo. O método da revisão integrativa nos estudos organizacionais. Gestão e Sociedade, Belo Horizonte, MG, v. 5, n. 11, p. 121-36, 2011.

BRASIL. Ministério do Desenvolvimento, Indústria e Comércio Exterior. Plano Estratégico de Desenvolvimento Econômico Territorial (PEDET) para 33 municípios pertencentes à microrregião do Vale do Piranga e microrregião da Zona da Mata Norte do Estado de Minas Gerais. Viçosa: UFV, 2015.

CALIXTO, Juliana Sena; RIBEIRO, Eduardo Magalhães; GALIZONI, Flávia Maria; MACEDO, Renato Luís Grisi. Trabalho, terra e geração de renda em três décadas de reflorestamentos no Alto Jequitinhonha. Revista de Economia e Sociologia Rural, São Paulo, SP, v. 47, n. 2, p. 519-538, julho/2009. Google Ecrossert

CERTEAU, Michel de. A invenção do cotidiano: artes de fazer. Petrópolis: Vozes, 1994.

COSTA, Bianca Aparecida Lima.; AMORIM JÚNIOR, Paulo Cesar Gomes; SILVA, Marcio Gomes da. As cooperativas de agricultura familiar e o mercado de compras governamentais em Minas Gerais. Revista de Economia e Sociologia Rural, Piracicaba, SP, v. 53, n. 1, p. 109-126, 2015. Google Ecrossret

COSTA, Lucas. A Agricultura Familiar e seu Impacto Econômico no Brasil e na América Latina. Conex. 12/02/2017. Acesso em: 05 out 2017. [Visualizar]

FERREIRA, Patrícia Aparecida; PEREIRA, José Roberto; ALENCAR, Edgard; SANTANA, Ana Carolina. Estado e agricultores familiares: uma análise interpretativa sobre o desenvolvimento rural no Sul de Minas Gerais. Revista de Economia e Sociologia Rural. Piracicaba, SP, v. 47, n. 3, p. 767-792, 2009. Google Ecrosset

FREITAS, Alair Ferreira de; FREITAS, Alan Ferreira de. Empreendimentos induzidos por políticas públicas: reflexões a partir do Programa de Combate à Pobreza Rural (PCPR) em Minas Gerais. Interações, Campo Grande, MT, v. 12, n. 2, p. 255-265, 2011. Google Ecrossset 
FREITAS, Alair Ferreira de; FREITAS, Alan Ferreira de. Interações entre organizações coletivas na promoção de desenvolvimento local. Interações, Campo Grande, MT, v. 14, n. 2, p. 177-188, 2013. Google Frossref

FREITAS, Alair Ferreira de; FREITAS, Alan Ferreira de. Os alicerces sociopolíticos do cooperativismo de crédito rural solidário na Zona da Mata de Minas Gerais. Revista de Economia e Sociologia Rural, Piracicaba, SP, v. 51, n. 3, p. 433-454, 2013. Google crosset

GRISA, Catia. Políticas públicas para a agricultura familiar no Brasil: produção e institucionalização das ideias. 2012. Tese (Doutorado em Ciências Sociais) - Universidade Federal Rural do Rio de Janeiro, Rio de Janeiro, RJ, 2012.

HESPANHOL, Antônio Nivaldo; PEREIRA, Claudinei da Silva. Região e regionalizações no estado de minas gerais e suas vinculações com as políticas públicas. Formação (Online), v. 1, n. 22, 2015. [Visualizar] Google

HESPANHOL, Rosângela Aparecida de Medeiros; COSTA, Vera Mariza Henriques de Miranda. Produção familiar: perspectivas de análise e inserção na microrregião geográfica de Presidente Prudente, SP. Acesso em: 05 maio 2016. [Visualizar]

INSTITUTO MINEIRO DE AGROPECUÁRIA - IMA. Região do Campo das Vertentes é reconhecida como produtora de Queijo Minas Artesanal. Nov. 2009. Acesso em: 14 de jun. 2015. [Visualizar]

LASCHEFSKI, Klemens Augustinus; DUTRA, Carina; DOULA, Sheila Maria. A legislação ambiental como foco de conflitos: uma análise a partir das representações sociais da natureza dos pequenos agricultores em Minas Gerais, Brasil. Sociedade \& Natureza, Uberlândia, MG, ano 24, n. 3, p. 405-418, 2012. [Visualizar] Google

MEIRELES, Selma. Informalidade nas relações de trabalho: uma expressão imediata da flexibilização dos modos de produção. In: SIMPÓSIO MINEIRO DE ASSISTENTES SOCIAIS, 3, 2013, Belo Horizonte. Anais... Belo Horizonte: Conselho Regional de Serviço Social de Minas Gerais, 2013. [Visualizar] Google

MENDES, Karina Dal Sasso; SILVEIRA, Renata Cristina de Campos Pereira; GALVÃO, Cristina Maria. Revisão integrativa: método de pesquisa para a incorporação de evidências na saúde e na enfermagem. Texto Contexto Enfermagem, Florianópolis, SC, v. 17, n. 4, p. 758-764, 2008. Google

MENDONÇA, Kenia Fabiana Cota; RIBEIRO, Eduardo Magalhães; GALIZONI, Flávia Maria; AUGUSTO, Hélder Anjos. Formação, sucessão e migração: trajetórias de duas gerações de agricultores do Alto Jequitinhonha, Minas Gerais. Revista Brasileira de Estudos de População, Rio de Janeiro, RJ, v. 30, n. 2, p. 445-463, 2013. [Visualizar] Google

MESQUITA, Lívia Aparecida Pires; MENDES, Estevane de Paula Pontes. Mulheres na agricultura familiar: a comunidade de Rancharia, Campo Alegre de Goiás (GO). In: ENCONTRO NACIONAL DE GEOGRAFIA AGRÁRIA, 21, 2012, Uberlândia, MG. Anais... Uberlândia-MG: UFU, 2012. Acesso em: 20 abr. 2016. [Visualizar] Google 
OLIVEIRA, Leandro Gomes de. Avaliação do Programa de Aquisição de Alimentos (PAA) e do Programa Nacional de Alimentação Escolar (PNAE) da agricultura familiar: estudo de caso na microrregião de Ubá-MG. 2015. 149 f. Dissertação (Mestrado em Engenharia da Produção) - Universidade Federal de São Carlos, São Carlos, SP, 2015. [Visualizar] Google

OLIVEIRA JÚNIOR, Lourival Batista de. Mata mineira: um estudo sobre a exclusão social e os limites e possibilidades das políticas de desenvolvimento territorial. 2010. 329 p. Tese (Doutorado em Administração) - Universidade Federal de Lavras, Lavras, MG, 2010.

PICOLOTTO, Everton Lazzaretti. Os atores da construção da categoria agricultura familiar no Brasil. Revista de Economia e Sociologia Rural, v. 52, p. 63-84, 2014. Google crossref

RIBEIRO, Eduardo Magalhães; AYRES, Eduardo Barbosa; GALIZONI, Flávia Maria; ALMEIDA, Ana Flávia; PEREIRA, Viviane Guimarães. Programas sociais, mudanças e condições de vida na agricultura familiar do Vale do Jequitinhonha Mineiro. Revista de Economia e Sociologia Rural, Piracicaba, SP, v. 52, n. 2, p. 365-386, 2014. Google crossref

RODRIGUES, Leila Ribeiro; THÉ, Ana Paula Glinfskoi. Veredas, oásis do sertão: conflito ambiental na apropriação das águas em Botumirim, MG. Sociedade \& Natureza, Uberlândia, MG, v. 26, n. 1, p. 25-36, 2014. Google crossref

RUA, Maria das Graças. Políticas públicas. Brasília, DF: CAPES/UAB, 2009. 130 p.

SECCHI, Leonardo. Políticas públicas: conceitos, esquemas de análise, casos práticos. São Paulo: Cengage Learning, 2010. 133 p.

SILVA, Adilson José da; SILVA JÚNIOR, Milton Ferreira Silva. Representações sociais e agricultura familiar: indícios de práticas agrícolas sustentáveis no Vale do Bananal - Salinas, Minas Gerais. Sociedade \& Natureza, Uberlândia, MG, v. 22, n. 3, p. 524-538, 2010. Google Ecrosser

SILVA, Márcio Gomes da; DIAS, Marcelo Miná; SILVA, Sandro Pereira. Relações e estratégias de (des)envolvimento rural: políticas públicas, agricultura familiar e dinâmicas locais no município de Espera Feliz (MG). Revista de Economia e Sociologia Rural, Piracicaba, SP, v. 52, n. 2, p. 229-248, 2014. Google Ecrossret

SIMÃO, Gustavo Leonardo; SILVA, Edson Arlindo; SILVEIRA, Suely de Fátima Ramos. Grau de cobertura do Programa de Aquisição de Alimentos (PAA) junto aos Agricultores Familiares do Estado de Minas Gerais. Revista de Economia e Sociologia Rural, Piracicaba, SP, v. 52, n. 3, p. 533-548, 2014. Google Ecrossret

SOUZA, Cecília. Políticas Públicas: uma revisão da literatura. Sociologias, n. 16, p. 20-45, 2006. [Visualizar] Google

TEIXEIRA, Elenaldo Celso. O papel das políticas públicas no desenvolvimento local e na transformação da realidade. Salvador: AATR, 2002. Acesso em: 05 maio 2016. [Visualizar] Google

WHITTEMORE, Robin; KNAFL, Kathleen. The integrative review: updated methodology. Journal of Advanced Nursing, Oxford, v. 52, n. 5, p. 546-553, 2005. Google crossref 